This item was submitted to Loughborough's Research Repository by the author.

Items in Figshare are protected by copyright, with all rights reserved, unless otherwise indicated.

\title{
Pinhole free thin film CdS deposited by chemical bath using a substrate reactive plasma treatment
}

PLEASE CITE THE PUBLISHED VERSION

http://dx.doi.org/10.1063/1.4828362

PUBLISHER

(c) AIP

VERSION

VoR (Version of Record)

LICENCE

CC BY-NC-ND 4.0

\section{REPOSITORY RECORD}

Lisco, Fabiana, Ali Abbas, Bianca Maniscalco, Piotr M. Kaminski, Maria Losurdo, Kevin Bass, Gianfranco Claudio, and Michael Walls. 2019. "Pinhole Free Thin Film Cds Deposited by Chemical Bath Using a Substrate Reactive Plasma Treatment”. figshare. https://hdl.handle.net/2134/13409. 


\section{Pinhole free thin film CdS deposited by chemical bath using a substrate reactive plasma treatment}

F. Lisco, A. Abbas, B. Maniscalco, P. M. Kaminski, M. Losurdo et al.

Citation: J. Renewable Sustainable Energy 6, 011202 (2014); doi: 10.1063/1.4828362

View online: http://dx.doi.org/10.1063/1.4828362

View Table of Contents: http://jrse.aip.org/resource/1/JRSEBH/v6/i1

Published by the AIP Publishing LLC.

\section{Additional information on J. Renewable Sustainable Energy}

Journal Homepage: http://jrse.aip.org/

Journal Information: http://jrse.aip.org/about/about_the_journal

Top downloads: http://jrse.aip.org/features/most_downloaded

Information for Authors: http://jrse.aip.org/authors

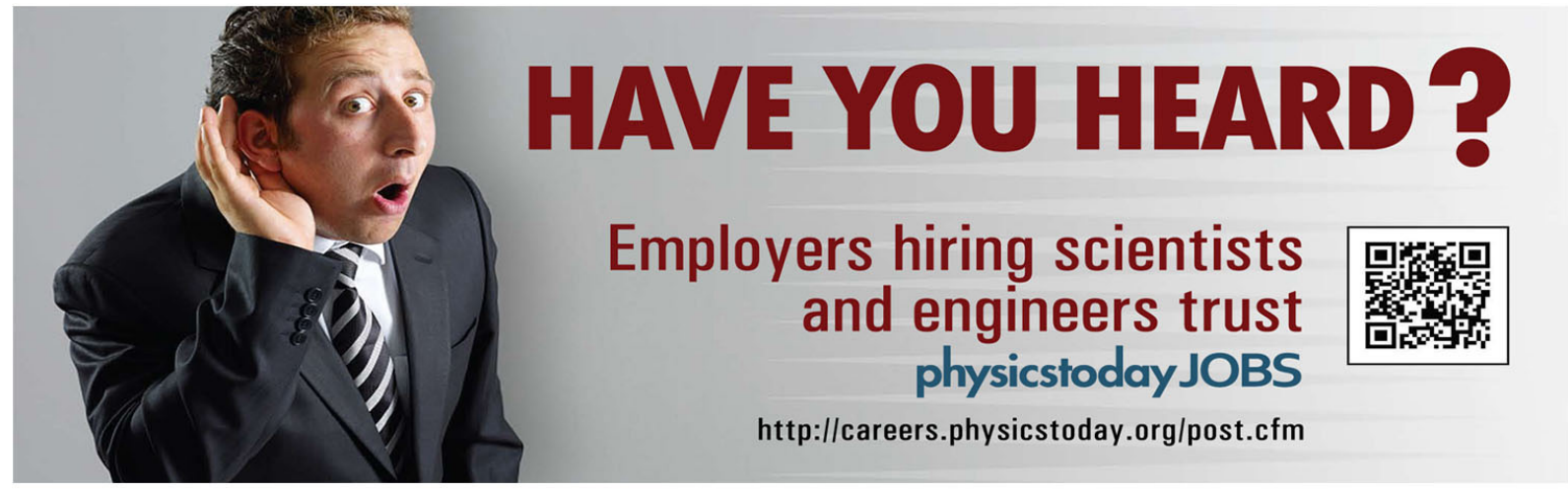




\title{
Pinhole free thin film CdS deposited by chemical bath using a substrate reactive plasma treatment
}

\author{
F. Lisco, ${ }^{1}$ A. Abbas, ${ }^{1}$ B. Maniscalco, ${ }^{1}$ P. M. Kaminski, ${ }^{1}$ M. Losurdo, ${ }^{2}$ \\ K. Bass, ${ }^{1}$ G. Claudio, ${ }^{1}$ and J. M. Walls ${ }^{1}$ \\ ${ }^{1}$ Centre for Renewable Energy Systems Technology (CREST), School of Electronic, \\ Electrical, and Systems Engineering, Loughborough University, Loughborough, \\ Leicestershire LE11 3TU, United Kingdom \\ ${ }^{2}$ Institute of Inorganic Methodologies and of Plasmas, IMIP-CNR, via Orabona 4, \\ 70126 Bari, Italy
}

(Received 29 May 2013; accepted 16 August 2013; published online 31 October 2013)

\begin{abstract}
Achieving a pinhole-free CdS layer is necessary to produce high performance thin film CdTe solar cells. Pinholes in the CdS layer can compromise the efficiency of a CdTe solar cell by causing shunts. We have investigated the use of a plasma treatment of a fluorine doped tin oxide coated glass substrate (NSG TEC 15) and its effect on pinhole reduction in thin film CdS layers grown by Chemical Bath Deposition. CdS films, $<100 \mathrm{~nm}$ thickness, were deposited on both $\mathrm{O}_{2} / \mathrm{Ar}$ plasma cleaned and conventionally cleaned substrates. We show that the $\mathrm{O}_{2} / \mathrm{Ar}$ plasma treatment of the TEC 15 substrate reduced the water contact angle from $\sim 55^{\circ}$ to less than $12^{\circ}$ indicating a substantial increase in the surface energy. The CdS deposited on the plasma treated TEC 15 was pinhole free, very smooth and homogenous in morphology and composition. Scanning electron microscopy images show that the $\mathrm{O}_{2} / \mathrm{Ar}$ plasma treatment is effective in increasing film density and grain size. Corresponding spectroscopic ellipsometry measurements show an increase in the refractive index from 2.18 to 2.43 at $550 \mathrm{~nm}$ wavelength. (C) 2013 AIP Publishing LLC. [http://dx.doi.org/10.1063/1.4828362]
\end{abstract}

\section{INTRODUCTION}

Surface treatment by plasma cleaning has been reported to be a useful process tool for more than $30 \mathrm{yr}$ in a broad range of applications spanning from microelectronics and photovoltaics (PVs) to automotive, textiles, medical, plastics, etc. ${ }^{1,2}$

Plasma cleaning is an effective and environmentally safe method for surface preparation. Activation of the surface of a material is important for the growth of thin films since surface contaminants and the native oxide can alter the growth mode and thin film adhesion. It can also affect the properties of the deposited films and therefore the performance of the PV devices. ${ }^{3,4}$

The surface properties of transparent conducting oxides (TCOs) have an influence on the quality of the other films comprising the cell. In particular, sputter treatments have been shown to reduce carbon contamination and modify the resulting interface between the $\mathrm{SnO}_{2}$ and the $\mathrm{CdS}$ layers. ${ }^{5}$ Poor growth regions, appearing as pinholes, can form in the n-type CdS layer, allowing a shunt path to develop between the front contact and the p-type CdTe film. ${ }^{6}$ Pinholes are particularly troublesome when a thin CdS layer is deposited on TCO-coated glass that has been cleaned using industry-standard techniques. ${ }^{\text {? }}$

Plasma treatments have previously been applied to TCOs such as indium tin oxide (ITO), ${ }^{1}$ aluminium-doped zinc oxide $(\mathrm{AZO}){ }^{8}$ and zinc oxide $(\mathrm{ZnO})^{9}$ with different gas combinations such as argon, hydrogen, or oxygen. These treatments have been shown to change the properties of the TCO surfaces.

In this paper, we discuss the plasma treatment of a commercially available fluorine doped tin oxide (FTO) transparent conducting oxide NSG TEC 15, which is used as superstrate in CdTe solar cell devices. 


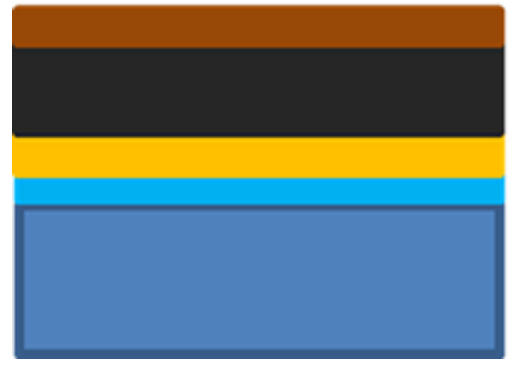

\section{Back contact CdTe CdS

FIG. 1. Schematic of a thin film CdTe solar cell in superstrate configuration.

A thin film CdTe solar cell consists of a multi-layer stack material system, with layers having specifically defined properties. Thin film CdTe solar cells are grown in a superstrate configuration as shown in Figure 1 on a FTO coated glass substrate. ${ }^{10}$ The light transmits through the TCO coated glass before reaching the p-n heterojunction, consisting of the n-type CdS layer and a p-type CdTe layer.

The plasma pre-treatment of the TEC 15 glass was performed to activate the surface prior to the chemical bath deposition (CBD) of the thin CdS film.

Good surface wettability of the TCO coated substrate is required to avoid the presence of the pinholes and ensure continuity in the deposited CdS thin films. Fluorine doped tin oxide is deposited on an industrial scale using an atmospheric pressure CVD process that results in a relatively rough surface. This roughness can increase the probability of pinhole formation. Here we report on the use of a plasma treatment process to grow pinhole-free CdS thin films on TEC 15 glass.

\section{EXPERIMENTAL}

TEC 15 glass supplied by NSG-Pilkington was used as the substrate material. TEC 15 is a multilayer stack of materials deposited on a $3.2 \mathrm{~mm}$ thick glass. The stack consists of a $25 \mathrm{~nm}$ $\mathrm{SnO}_{2}$ layer, a $25 \mathrm{~nm} \mathrm{SiO}{ }_{2}$ layer, and a $280 \mathrm{~nm}$ thick conducting layer of fluorine doped tin oxide $\left(\mathrm{SnO}_{2}: \mathrm{F}\right)$. TEC 15 has a sheet resistance of $15 \Omega / \square$ and a relatively good transparency, $\sim 82 \%$ light transmittance. These properties are a good compromise between the electrical and the optical requirements of a PV device substrate. The substrate was treated using $20 \mathrm{sccm}$ $\mathrm{O}_{2} / 30 \mathrm{sccm}$ Ar plasma for $5 \mathrm{~min}$ prior to the $\mathrm{CdS}$ film growth. The plasma power was set at $100 \mathrm{~W}$ and at a pressure of between 335 and 273 mTorr. Electrodes and sample trays are $406.4 \mathrm{~mm} \times 406.4 \mathrm{~mm}$ in area using perforated aluminium of thickness $3.175 \mathrm{~mm}$. The parallel electrodes are used to provide uniform plasma across the sample area. All substrate surfaces are treated to the same degree, irrespective of their position on the sample tray. The plasma treatment reactor, Glen100-P AE Advanced Energy, was a parallel plate system using AC plasma power source with potential for three gas admittance lines. The system was pumped to a pre-process pressure of $332 \mathrm{mT}$ Torr using a rotary pump.

A $50 \mathrm{~nm}$ CdS thin film was deposited by CBD, the reaction occurs in a beaker immersed in a water jacket to ensure constant temperature $\left(70^{\circ} \mathrm{C}\right)$. The bath solution was made of $200 \mathrm{ml}$ of de-ionized water, $15 \mathrm{ml}$ of $\mathrm{Cd}\left(\mathrm{CH}_{3} \mathrm{COO}\right)_{2} \quad 0.01 \mathrm{M}, 25 \mathrm{ml}$ of $\mathrm{NH}_{4} \mathrm{OH} 25 \%$, and $10 \mathrm{ml}$ of $\mathrm{CS}\left(\mathrm{NH}_{2}\right)_{2}$. A magnetic bar was used to stir the solution to accelerate the reaction kinetics.

\section{RESULTS AND DISCUSSION}

\section{A. Substrate surface modification}

Plasma treatment activates the substrate surface by increasing the surface energy. The surface energy of the material was tested by measuring the water contact angle before and immediately after the treatment. Figure 2 shows the effect of the plasma treatment on the FTO coated glass surface. The equilibrium contact angle that the drop makes with the surface is $54.3^{\circ}$ 

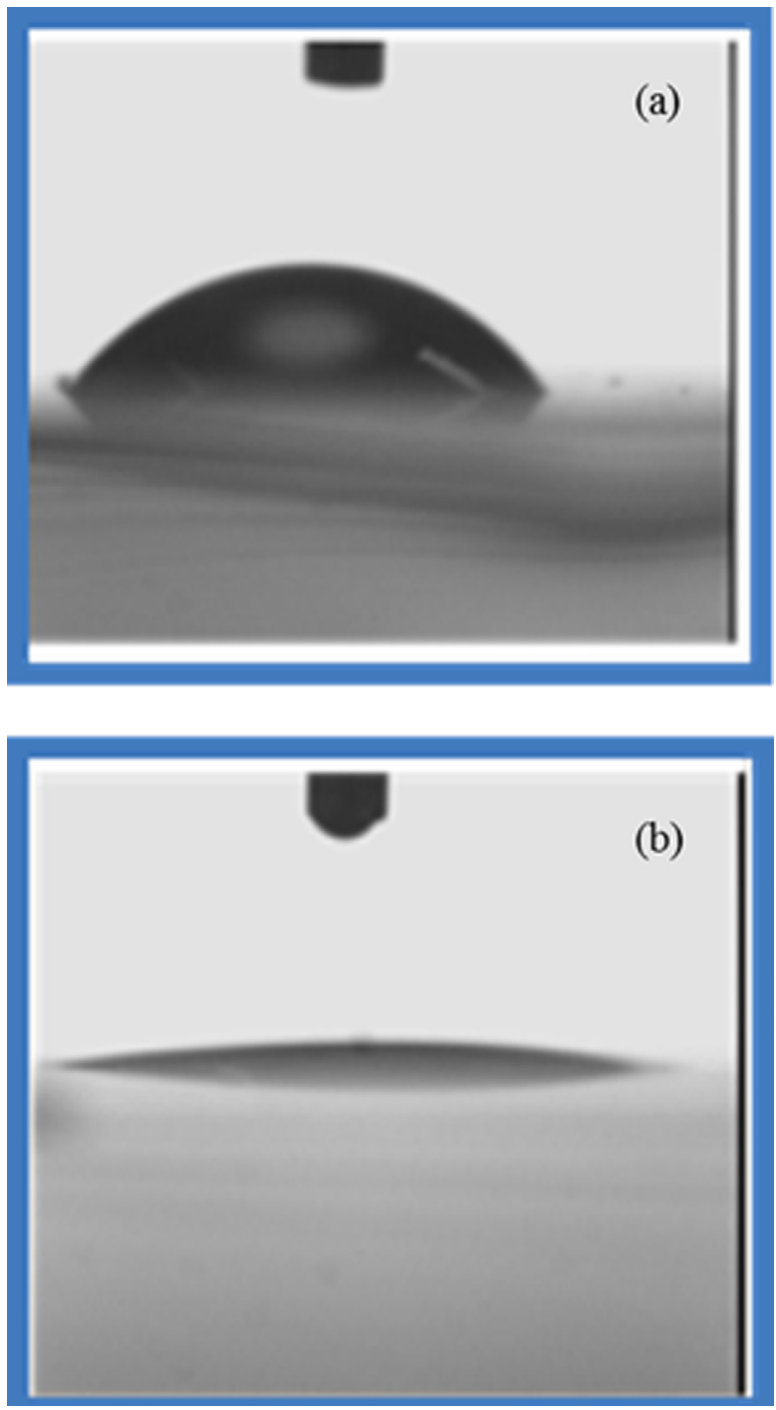

FIG. 2. Water contact angle images (a) prior and (b) post plasma treatment.

before the treatment and $12.3^{\circ}$ after the plasma treatment. This indicates that the treatment increases the hydrophilic nature of the surface. The increased surface energy is beneficial for adhesion and the continuity of the thin film. It is possible that the increase in surface energy may change the thin film growth kinetics. However, there was only a marginal difference in thin film thickness $(\sim 50 \mathrm{~nm})$ for films deposited on the treated and untreated surfaces as measured by spectroscopic ellipsometry. Hence a valid comparison was possible between their properties.

This hydrophilic behaviour corresponds to the removal of contaminates from the surface, as confirmed by X-ray photoelectron spectroscopy (XPS) analysis. Table I reports the atomic

TABLE I. Atomic \% composition as determined by XPS.

\begin{tabular}{lcc}
\hline \hline & Untreated & Plasma treated \\
\hline $\mathrm{C} 1 \mathrm{~s} \%$ & 24.5 & 11.9 \\
$\mathrm{O} 1 \mathrm{~s} \%$ & 46.3 & 55.2 \\
$\mathrm{Sn3d} \%$ & 27.3 & 31.4 \\
\hline \hline
\end{tabular}


percentage of Carbon (C1s), Oxygen (O1s), and Tin ( $\mathrm{Sn} 3 \mathrm{~d})$ for the untreated and the plasma treated substrates, indicating carbon contamination reduction without altering the $\mathrm{Sn} / \mathrm{O}$ ratio.

\section{B. Impact of substrate plasma treatment on the CdS films}

Scanning white light interferometry (SWLI) is a powerful tool for the metrology of surfaces. We use a variant of SWLI called Coherence Correlation Interferometry $(C C I)$ developed by Taylor Hobson, Ltd. The CCI technique was used to analyse the surface morphology of the CdS films and detect pinholes in the CdS. Pinholes appear as spikes in the CCI surface image as shown in Figure 3(a). In this case the CdS was deposited on the untreated substrate; pinholes were detected with a mean depth of $55 \mathrm{~nm}$ and a width of $0.65 \mu \mathrm{m}$ as shown in Figure 4. The spatial resolution of the CCI is determined by the wavelength of light and the numerical aperture of the lens used and is typically $\sim 0.3 \mu \mathrm{m}$. The vertical resolution is typically $<1 \mathrm{~nm}$.

The CCI analysis shows that the pinhole density was dramatically decreased and virtually eliminated for the film grown on the plasma treated substrate (Fig. 3(b)); the thin film also has a smoother surface.

Scanning Electron Microscopy (SEM) images were obtained to study the surface morphology of the grown CdS films. Figure 5 shows the comparison between the surface of the untreated (a) and the plasma treated (b) samples. The CdS films exhibit a crystalline structure with grain size increasing from $\sim 108 \mathrm{~nm}$ to $\sim 175 \mathrm{~nm}$ following plasma treatment of substrate.
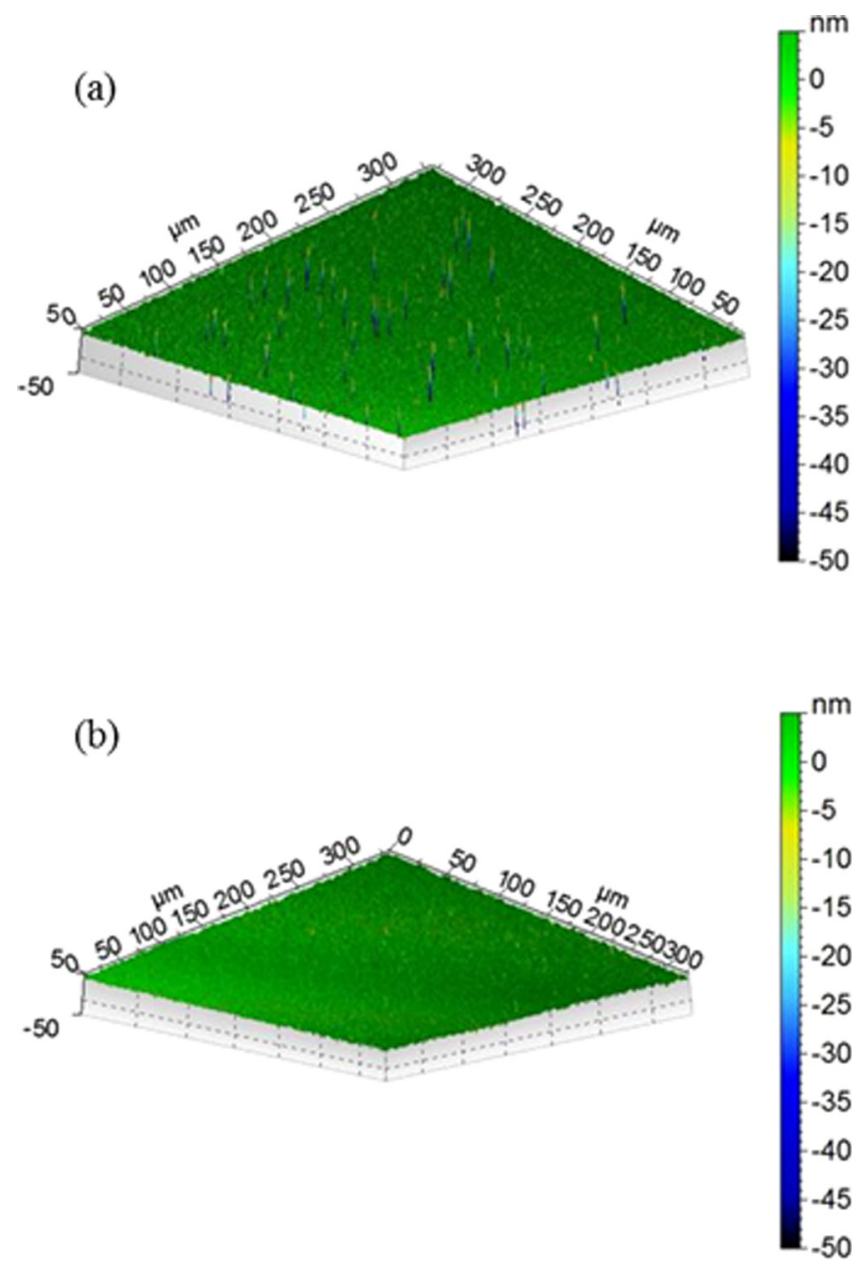

FIG. 3. Three dimensional CCI images of CdS deposited on (a) untreated and (b) plasma treated substrates $(20 \mathrm{sccm}$ $\mathrm{O}_{2} / 30 \mathrm{sccm}$ Ar). 


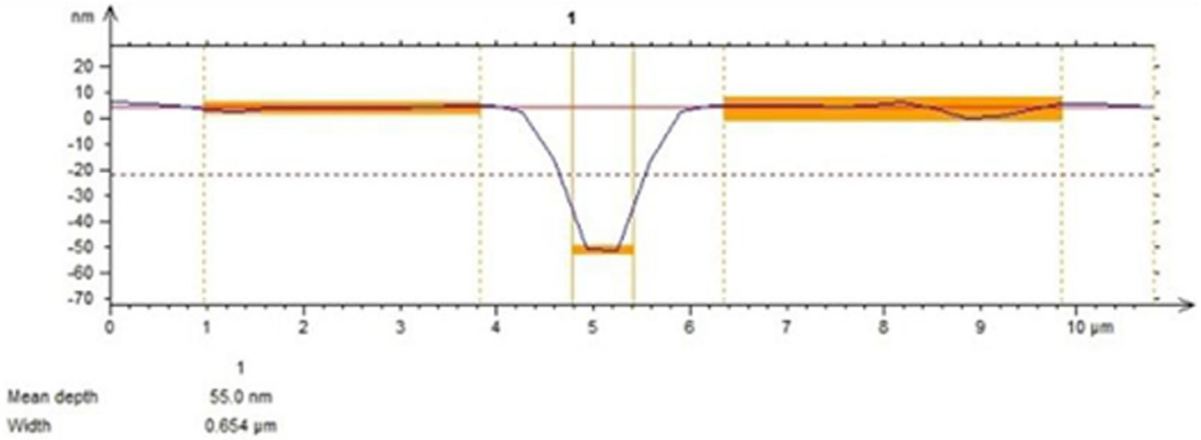

FIG. 4. Mean depth and width of pinholes in CdS observed on the surface of the untreated samples. The thickness of the CdS layer was $50 \mathrm{~nm}$.

The treated samples generally showed more uniform coverage of the surface with a more compact deposited film.

XPS analysis was also performed on the CdS films to analyse their stoichiometry. Figure 6(a) shows the XPS spectra of Cd3d and S2p photoelectron core levels for the untreated
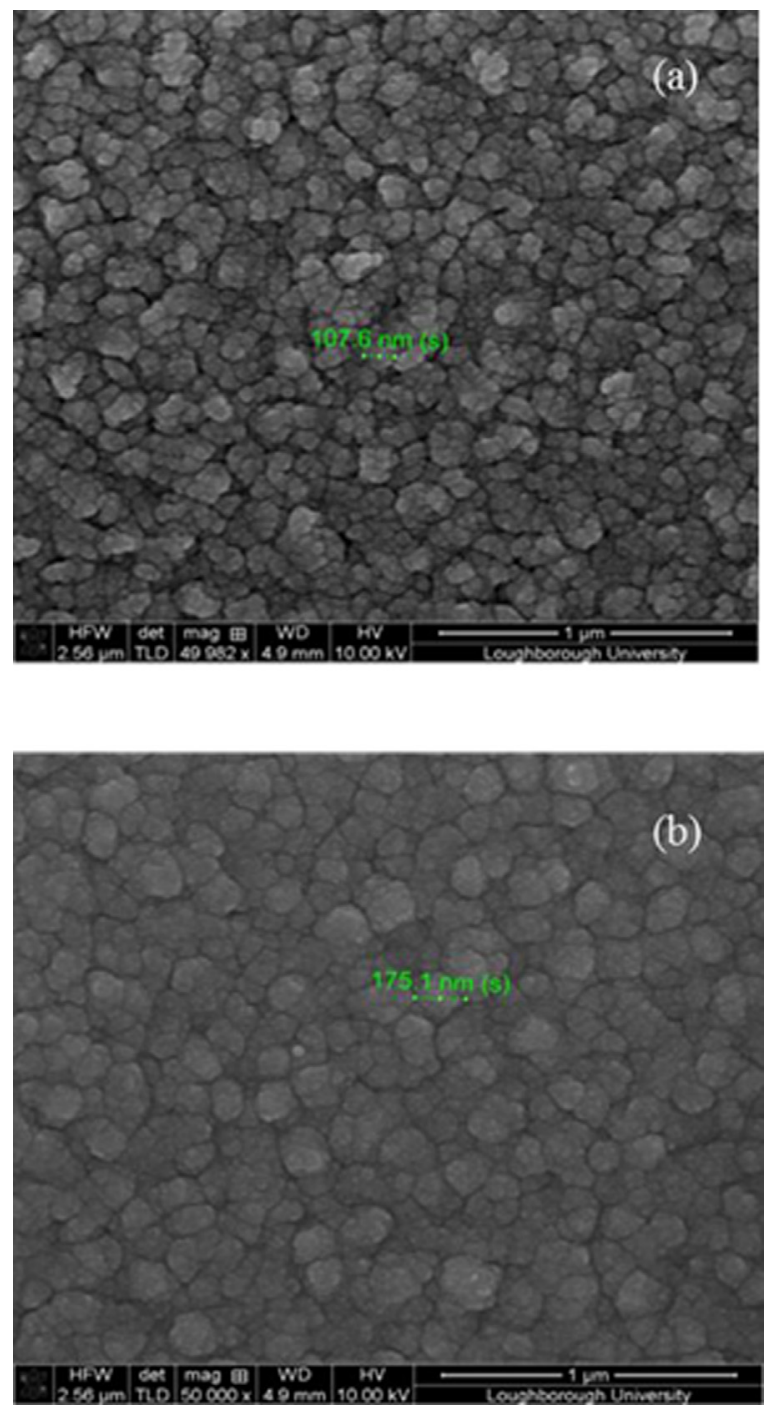

FIG. 5. SEM images of CdS films grown on (a) untreated and (b) plasma treated ( $\left.20 \% \mathrm{O}_{2} / 30 \% \mathrm{Ar}\right)$ FTO coated glass. 

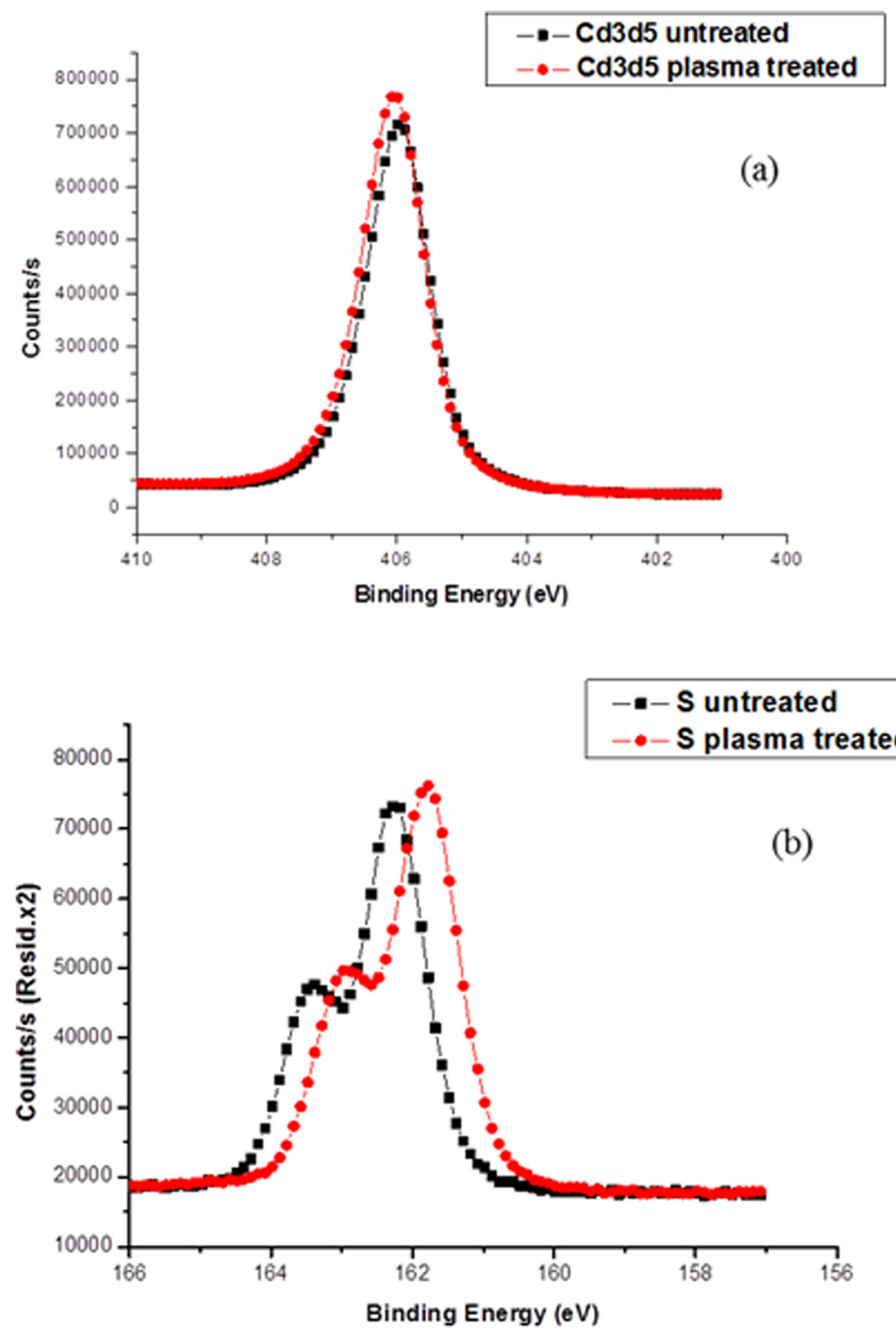

FIG. 6. XPS measurements of samples untreated and plasma treated $\left(20 \mathrm{sccm} \mathrm{O}_{2}\right)$ for $\mathrm{Cd} 3 \mathrm{~d} 5 / 2$ (a) and $\mathrm{S} 2 \mathrm{p}$ peak (b).

and the plasma treated samples. The position of the peak at $405.8 \mathrm{eV}$ for $\mathrm{Cd}$ orbital $3 \mathrm{~d}_{5 / 2}$ and the shape and binding energy of 161.6 and $162.8 \mathrm{eV}$ for $\mathrm{S} 2 \mathrm{p}_{3 / 2}$ and $\mathrm{S} 2 \mathrm{p}_{1 / 2}$, match the theoretical $\mathrm{CdS}$ values, ${ }^{11}$ indicating that $\mathrm{CdS}$ was not incorporating oxygen into the films.

The optical properties of the CdS films were measured using spectroscopic ellipsometry. Transmission and reflection measurements were obtained using a spectrophotometer. The TaucLorentz model ${ }^{12}$ was used to parameterise the spectral dependence of the CdS refractive index, $\mathrm{n}$, and extinction coefficient, k. The derived optical properties are shown in Figure 7. The CdS film deposited on the plasma treated substrate showed increased refractive index (Figure 7(a)). The film also showed increased absorption and a red-shift of the absorption edge (Figure 7(b)). This is consistent with the increased grain size, increased compactness, and reduced pinhole density observed for the film deposited on the plasma treated substrate.

Figure 8 shows the transmittance and reflectance spectra of the CdS thin films deposited on the untreated and on the plasma treated substrates. The transmittance of the thin films reaches a maximum of $\sim 80 \%$ and it decreases near the absorption edge at $500 \mathrm{~nm}$; this confirms that the CdS has good crystallinity. ${ }^{13}$ 

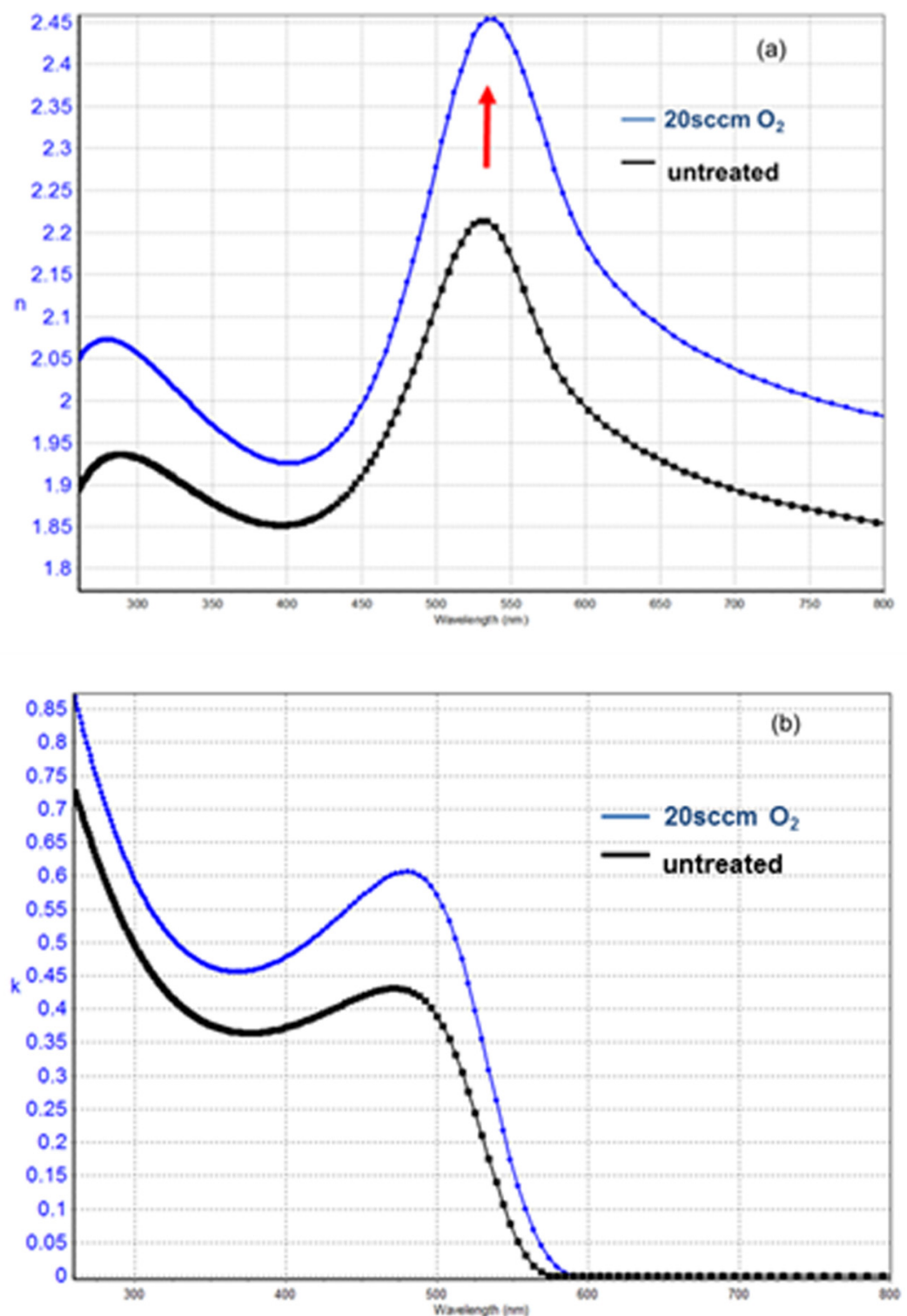

FIG. 7. n (a) and k (b) dispersions measured for CdS films deposited on the untreated substrate and the plasma treated substrate $\left(20 \mathrm{sccm}\right.$ of $\left.\mathrm{O}_{2}\right)$.

The CdS deposited on the plasma treated substrate shows lower transmission compared to the film deposited on the untreated substrate. The transmittance is lower due to the higher optical density of the CdS film as shown by the SEM measurements and the removal of pinholes as shown by the CCI metrology measurements. The Urbach equation can be used to obtain the absorption coefficient, ${ }^{14}$ it is defined by formula

$$
\alpha=\frac{A\left(\boldsymbol{h v}-\boldsymbol{E}_{g}\right)^{p}}{\boldsymbol{h} v}
$$

where $\mathrm{A}$ is a constant, $\mathrm{E}_{\mathrm{g}}$ is the band gap energy, $\nu$ is the frequency, $\mathrm{h}$ is the Plank's constant, $\mathrm{p}$ is the numerical coefficient. In Figure $9,[\alpha \mathrm{h} \nu]^{2}$ is shown as a function of the energy $(\mathrm{eV}), \mathrm{p}$ in this case is 0.5 . The single slope in the curve explains the direct transition of electrons between the valence band and the conduction band. Extrapolating the linear region of $[\alpha]^{2}$ up to the value $\alpha=0$, the band gap energy $\left(\mathrm{E}_{\mathrm{g}}\right)$ is determined to be $2.3 \mathrm{eV}$. 


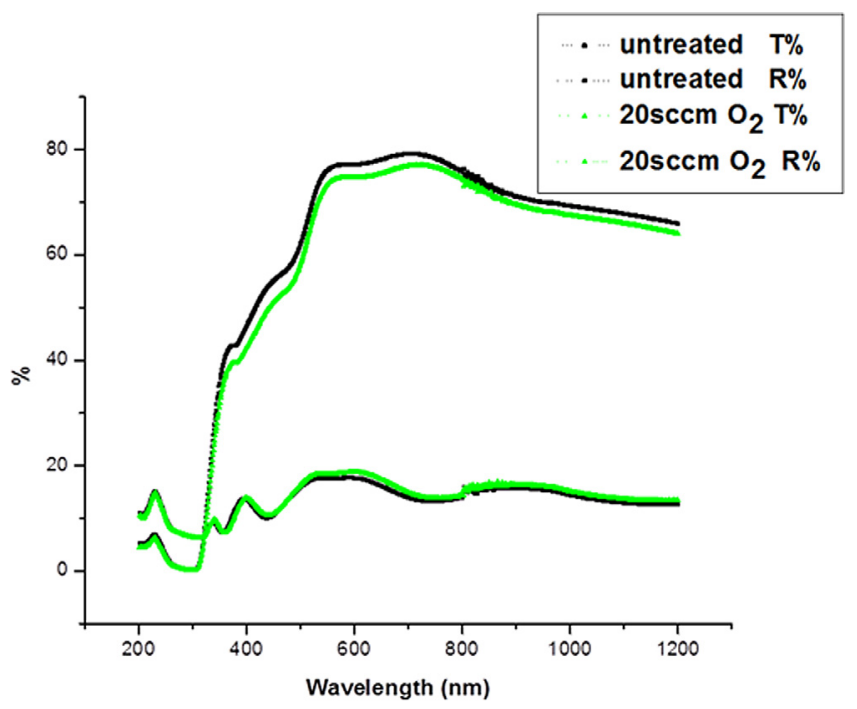

FIG. 8. Transmission and reflection spectra for CdS thin films deposited on TEC 15, comparing the untreated and the plasma treated surface, with $20 \mathrm{sccm}$ of $\mathrm{O}_{2}$.

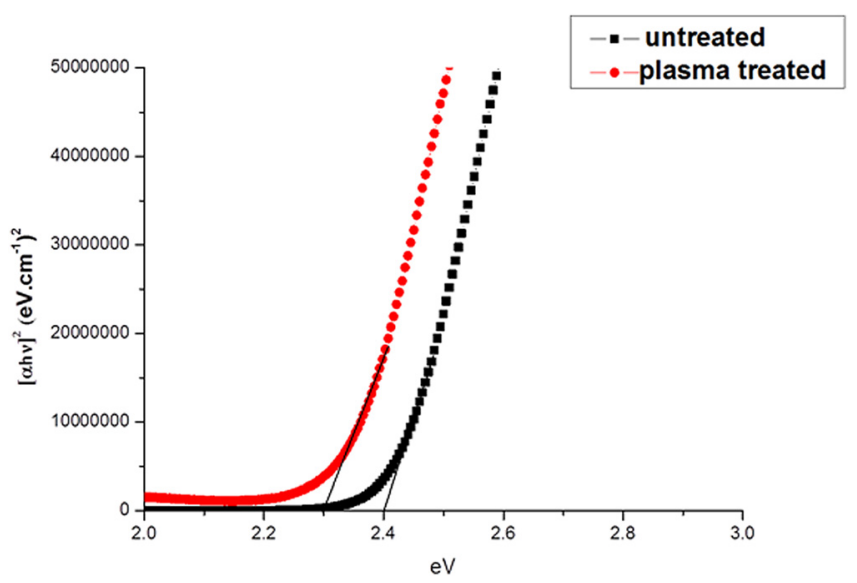

FIG. 9. Energy band gap $\left(E_{g}\right)$ of the untreated and plasma treated sample, estimated from the $[\alpha h \nu]^{2}=f(h \nu)$, by using the Urbach equation.

The band gap decreased from $2.4 \mathrm{eV}$ to $2.3 \mathrm{eV}$ as a result of the substrate plasma cleaning due to the increased density of the film or the small grain size. ${ }^{15}$

\section{CONCLUSIONS}

Plasma cleaning of FTO-coated glass prior to the deposition of the CdS/CdTe solar cell strongly affects the TCO surface, and improves the quality of the subsequently deposited $\mathrm{CdS}$ thin film. Specifically, the plasma cleaned FTO exhibits increased hydrophilic behaviour, due to a reduction or elimination of surface contamination. This corresponds to a reduction in water contact angle and increased surface energy. When CdS thin films are deposited on to a plasma cleaned FTO surface we have shown that the pinhole density is greatly reduced and virtually eliminated compared with CdS films deposited on substrates treated using standard wet cleaning techniques.

The plasma treatment improves the wettability of the substrate as demonstrated using water contact measurements. This improves the optical and morphological properties of the deposited $\mathrm{CdS}$ thin films, resulting in a higher refractive index and a higher absorption coefficient related 
to the increased film density and increased grain size of CdS film. The pinhole removal and the increased density allow the use of a much thinner CdS layer. Use of a thinner CdS layer actually reduces absorption of blue spectrum photons thereby increasing the efficiency of the thin film CdTe cell. Further experiments are now planned to incorporate the plasma cleaning process into a full cell deposition process to assess the improvement to device performance.

${ }^{1}$ C. C. Wu, C. I. Wu, J. C. Sturm, and A. Kahn, "Surface modification of indium tin oxide by plasma treatment: An effective method to improve the efficiency, brightness, and reliability of organic light emitting devices," Appl. Phys. Lett. 70(11), 1348 (1997).

${ }^{2}$ W. Petasch, B. Kegel, H. Schmid, K. Lendenmann, and H. Keller, "Low-pressure plasma cleaning: A process for precision cleaning applications," Surf. Coat. Technol. 97(1-3), 176-181 (1997).

${ }^{3}$ M. Losurdo, M. M. Giangregorio, F. Lisco, P. Capezzuto, G. Bruno, S. D. Wolter, M. Angelo, and A. Brown, "InAs (100) surfaces cleaning by an as-free low-temperature $100^{\circ} \mathrm{C}$ treatment," J. Electrochem. Soc. 156(4), H263 (2009).

${ }^{4}$ M. Tucci, E. Salurso, F. Roca, and F. Palma, "Dry cleaning process of crystalline silicon surface in a-Si:H/c-Si heterojunction for photovoltaic applications," Thin Solid Films 403-404, 307-311 (2002).

${ }^{5}$ M. Tuleta, "Effect of argon plasma on the float glass surface," Acta Phys. Pol. A 120, 91-93 (2011).

${ }^{6} \mathrm{~F}$. Collins, "Morphology of CdS thin films: Pinholes and their effect on open circuit Voltage in CdS/CdTe solar cells," in 37th IEEE Photovoltaic Specialists Conference (PVSC) (2011), pp. 1700-1704.

${ }^{7}$ K. L. Chopra, P. D. Paulson, and V. Dutta, "Thin-film solar cells: An overview," Prog. Photovoltaics 12(23), 69-92 (2004).

${ }^{8}$ T. Minami, H. Sato, H. Nanto, and S. Takata, "Heat treatment in hydrogen gas and plasma for transparent conducting oxide films such as $\mathrm{ZnO}, \mathrm{SnO}_{2}$, and indium tin oxide," Thin Solid Films 176, 277-282 (1989).

${ }^{9}$ A. Y. Polyakov, N. B. Smirnov, A. V. Govorkov, K. Ip, M. E. Overberg, Y. W. Heo, D. P. Norton, S. J. Pearton, B. Luo, F. Ren, and J. M. Zavada, "Hydrogen plasma treatment effects on electrical and optical properties of n-ZnO," J. Appl. Phys. 94(1), 400 (2003).

${ }^{10}$ B. E. Mccandless and J. R. Sites, "Cadmium Telluride Solar Cells" in Handbook of Photovoltaic Science and Engineering, 1st ed. (John Wiley \& Sons, 2003).

${ }^{11}$ D. A. Mazón-Montijo, M. Sotelo-Lerma, L. Rodríguez-Fernández, and L. Huerta, "AFM, XPS, and RBS studies of the growth process of CdS thin films on ITO/glass substrates deposited using an ammonia-free chemical process," Appl. Surf. Sci. 256(13), 4280-4287 (2010).

${ }^{12}$ H. Fujiwara, Spectroscopic Ellipsometry Principles and Applications, 1st ed. (Wiley, 2007).

${ }^{13}$ Y. Thomas, "An essay on the cohesion of fliuds," Philos. Trans. R. Soc. London 95, 65-87 (1805).

${ }^{14}$ J. Sajeev, C. Costas, M. H. Cohen, and E. N. Economou, "Theory of electron band tails and the Urbach opticalabsorption edge," Phys. Rev. Lett. 57, 1777-1780 (1986).

${ }^{15}$ A. E. Rakhshani and A. S. Al-Azab, "Characterization of CdS films prepared by chemical-bath deposition," J. Phys.: Condens. Matter 12, 8745-8755 (2000). 